\title{
El POBlado de El CERRO de la horCa (Plasenzuela, CACERES). DATOS PARA LA SECUENCIA DEL NEOLITICO TARDIO Y LA EDAD DEL COBRE EN LA ALTA EXTREMADURA
}

\author{
POR \\ ANTONIO GONZALEZ CORDERO \\ MANUEL DE ALVARADO GONZALO \\ LUCIANO MUNICIO GONZALEZ \\ FERNANDO PIÑON VARELA
}

\begin{abstract}
RESUMEN Se efectúa la presentación de este yacimiento cuyos vestigios inducen a identificar dos ocupaciones distintas: una correspondiente al Neolítico Tardio (CH.1) caracterizada por la presencia de abundantes cerámicas decoradas con técnica de boquique, y, tras un hiatus, otra perteneciente a un habitat de la Edad del Cobre en sus fases Plena y Final.

ABSTRACT This paper is a preliminary report on the recently excavated site of Cerro de la Horca in Extremadura. The site has two phases: the first (C. H. I.), dating to the Later Neolithic, has a great deal of pottery decorated by the "boquique» technique; following a hiatus in the site's occupation, the second phase (C. H. II) belongs to the Middle (or Full) and Late Chalcolithic.
\end{abstract}

Palabras clave Secuencia evolutiva. Neolítico tardío. Edad del Cobre. Alta Extremadura.

\section{LOCALIZACION Y MEDIO FISICO}

El yacimiento del "Cerro de la Horca" está situado en el borde meridional de la penillanura Trujillano-Cacereña, dentro del término municipal de Plasenzuela (Fig. 1). Sus coordenadas geográficas son $39^{\circ} 22^{\prime} 44^{\prime \prime} \mathrm{N}$ y $6^{\circ} 02^{\prime} 00^{\prime \prime}$ WG, referidas a la Hoja 705-«Trujillo" del M.T.N. a escala 1:50.000 del I.G.N.

El poblado se enclava en el apéndice de un batolito granítico que presenta en su parte más elevada una plataforma de unos $40 \mathrm{~m}$. de diámetro máximo y que destaca alrededor de $50 \mathrm{~m}$. sobre el terreno circundante. Esta característica confiere al asentamiento una clara posición estratégica que se acentúa aún más por el encajamiento de la red fluvial inmediata (Arroyos de la Jarilla y de los Asnos). 


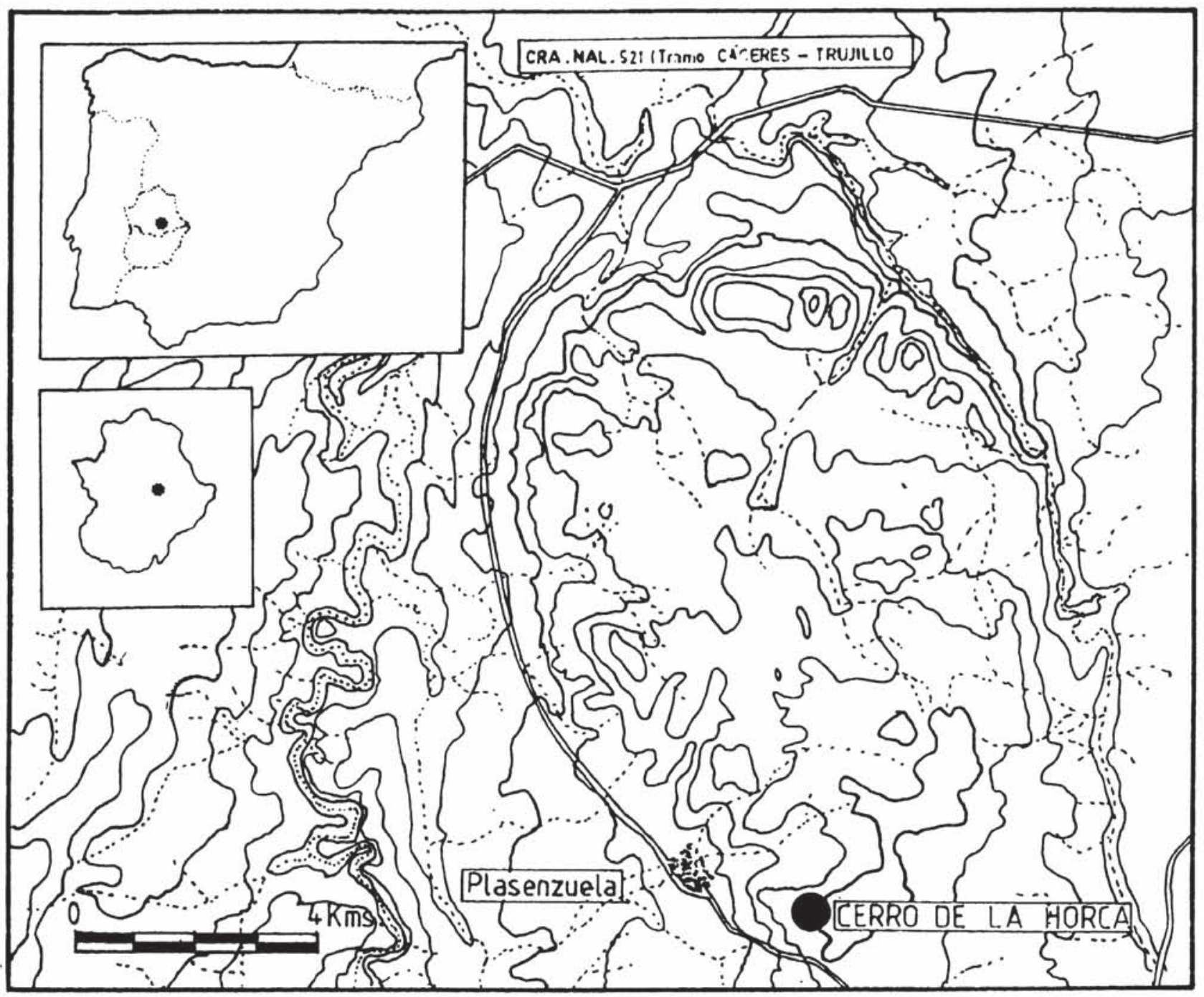

FIG. 1.- Localización geográfica del Cerro de la Horca.

A grandes rasgos, la estructura geológica de la zona de Plasenzuela puede definirse por la existencia de un pizarral Precámbrico y afloramientos graníticos del Terciario, que han dado lugar a unas formas de relieve relativamente suaves. En este paisaje destacan los afloramientos graníticos como el Cerro de la Horca, consecuencia de un fenómeno de erosión diferencial.

Lo más destacado de esta zona de contacto es la presencia de gran número de afloramientos acuiferos y la formación de filones o bolsadas metalíferas cuya explotación se ha mantenido hasta principios del presente siglo. Fundamentalmente, se trata de blendas, galenas argentíferas, casiteritas y arsenopiritas.

En lo que al aspecto agrícola se refiere, los cultivos actuales, exceptuando las pequeñas huertas, son los típicos de las tierras de secano, con trigo, cebada, centeno, etc., junto con olivos e higueras. De este modo, el Cerro de la Horca está ocupado por un olivar instalado en bancales que han cambiado la configuración originaria del terreno. Ya en el pie del Cerro, se desarrolla una vegetación típicamente mediterránea, caracterizada por encina, acebuche, monte bajo, etc.

Tuvimos conocimento de la existencia del yacimiento por medio de la noticias proporcionadas por el propietario del terreno a dos de los firmantes (A.G.C. y M.A.G.), acerca de la abundancia de 
restos arqueológicos que aparecían en el lugar cada vez que se procedia a realizar trabajos de roturación en los bancales del olivar. En vista de ello, se procedió a un inmediato reconocimiento y prospección de la zona que deparó indicios suficientes como para suponer la existencia de un asentamiento prehistórico de cierta importancia.

Dada la escasez de datos existentes sobre la Edad del Cobre en Extremadura, y al amparo del programa de investigaciones que sobre este período se desarrolla por el Museo Provincial de Cáceres, se solicitó el preceptivo permiso de excavación a la Dirección del Patrimonio de la Consejería de Cultura de la Junta de Extremadura, cuya concesión permitió llevar a cabo varias actuaciones arqueológicas sistemáticas (1984-1987), a las que haremos referencia en conjunto.

\section{PLANTEAMIENTO DE LOS TRABAJOS}

La gran cantidad de materiales que se encontraban dispersos por toda la superficie del Cerro, como consecuencia de las constantes remociones de tierra realizadas por los arados, motivó que, como primer objetivo, se planeara una sistemática recogida de materiales de superficie (área delimitada por un círculo en el esquema topográfico de la Figura 1), con el fin de obtener datos suficientes que pudieran ayudar a conseguir una valoración más completa del yacimiento, ilustrando la posible secuencia de su ocupación. Se pretendía con esta actuación, igualmente, determinar las posibles zonas de mayor interés para el posterior trabajo de excavación. En definitiva, se perseguía la obtención de una referencia capaz de articular la información arqueológica - un tanto dispersaregistrada en este territorio, para así, en lo posible, cotejarla con la brindada por las zonas aledañas.

Para el desarrollo de la excavación propiamente dicha, se escogieron tres zonas a diferentes alturas, con el objeto de localizar posibles áreas de ocupación y establecer sus respectivas comparaciones estratigráficas (Fig. 2). Así se han planteado distintos cortes sobre la meseta de este domo ( $\mathrm{M}$ "), en su ladera ("L») y al pie de esta, o base ("B»), totalizando 18 cuadrículas de $4 \mathrm{~m} / 2$ y $16 \mathrm{~m} / 2$.

En la primera de ellas, o superior, los 9 cortes abiertos han atestiguado una ocupación perteneciente a la Edad del Cobre. A lo largo de su desarrollo estratigráfico, pueden distinguirse, al menos dos períodos, según la presencia/ausencia de ciertos elementos como, en particular, la cerámica campaniforme, constatada tan sólo en las capas superiores. Por lo demás, el conjunto del equipamiento doméstico de esta comunidad permanece aparentemente estable, manteniendose los mismos elementos industriales, en conjunto, correspondientes a un desarrollo ya pleno del Calcolítico.

En la ladera, el único corte excavado, atestiguó la total alteración del relleno arqueológico por la actividad antrópica reciente, si bien, el grueso de los materiales hallados presentan notables afinidades con el lote recuperado en la meseta, con aparición igualmente de tipos campaniformes.

Por último, en la base del Cerro, los 8 cortes excavados arrojan quizá la evidencia más interesante, pues se registran dos grandes fases de ocupación. Una de ellas, la más reciente, análoga a la advertida tanto en la meseta como - revuelta - en la ladera; la otra, caracterizada por la aparición. de diversos tipos de cerámicas decoradas, correspondiente a época tardoneolítica. Entre ambas media un nivel de granito descompuesto, arqueológicamente estéril, que garantiza esta diferenciación preliminar.

La estratigrafía de este sector del Cerro es un tanto homogénea y reiterativa. Solamente cabe destacar que, la potencia de esta capa estéril decrece conforme nos alejamos del batolito, como consecuencia de su erosión.

\section{UNIDADES ESTRATIGRAFICAS}

Sobre esta base puede avanzarse la ocupación del sitio desde época tardoneolítica hasta los 


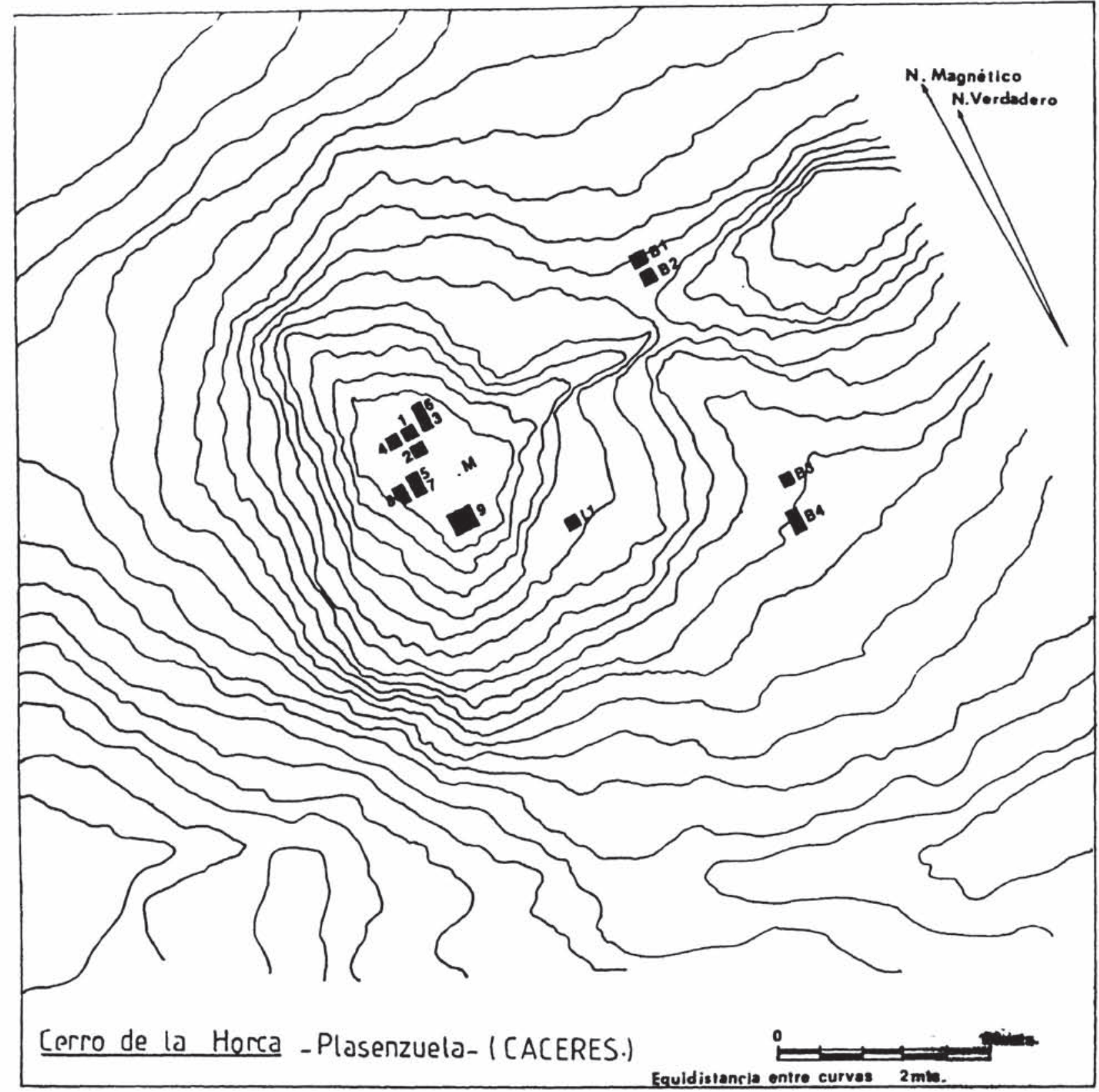

FIG. 2.-Localización de los cortes abiertos en el cerro, hasta septiembre de 1986.

epígonos de la Edad del Cobre, significados por el hallazgo de especies campaniformes cuyas decoraciones se incluyen en la órbita de Ciempozuelos y grupos afines. Por desgracia, esta secuencia, de una potencia estratigráfica media de $1,20 \mathrm{~m}$., no muestra una continuidad cultural, sin que, por el momento, en ninguno de los cortes excavados haya sido posible advertir ningún tipo de vinculación entre las utilizaciones neolítica y calcolítica del Cerro.

\section{El Neolítico}

La atribución neolítica de la primera ocupación del Cerro de La Horca, proviene de la caracteri- 
zación tipológica del conjunto de materiales recuperados. En los perfiles estratigráficos esta fase se desarrolla en una potencia media de $20-30 \mathrm{cms}$., localizándose el techo de la capa a una profundidad de $1,00 \mathrm{~m}$. Se asienta directamente sobre el lecho granítico, cuya disgregación le confiere una coloración amarillenta y textura granulosa y compactada. En ella se registran diversos materiales fracturados, entre los que adquiere un marcado protagonismo como elemento definidor el lote de cerámicas (Fig. 3).

El primer dato a considerar es la mayoritaria presencia de cerámicas decoradas frente a las especies lisas. La representación más numerosa y, a la vez, que mejor caracteriza este horizonte está constituida por los tipos decorados con técnica de boquique, entre los cuales y prescindiendo de cuestiones relacionadas con factura o perfección de diseño, se observa una tendencia a agrupar las decoraciones en motivos lineales - rectilíneos o curvilíneos- y paralelos, ordenados en algún caso a partir de elementos en relieve (mamelones). En ocasiones, las bandas de boquique se hallan festoneadas por líneas de pequeñas impresiones triangulares.

Se observa también la existencia de motivos incisos o impresos sobre los bordes y algunos elementos en relieve -mamelones, cordones impresos- como motivos decorativos. Igualmente, se recoge la presencia de algunas asas de cinta y como elementos aislados, de dos fragmentos incisos, uno con un triángulo invertido relleno de líneas más o menos verticales de muy tosca ejecución, y otro con líneas verticales que parten del borde.

En cuanto al conjunto de cerámicas lisas, de morfología similar a las de los tipos precedentes, merece destacarse la presencia de una cazuela de carena baja con paredes rectas, una fuente de perfil bajo con labio ensanchado y aplanado y un fragmento de borde engrosado, perteneciente a una olla globular. Junto con ellos, los cuencos de perfil semiesférico y los de paredes rectas constituyen el lote más abundante de este conjunto cerámico.

Por su parte, la industria lítica es bastante pobre, faltando evidencias relativas a útiles pulimentados al igual que sobre los elementos de trituración y molienda. El utillaje tallado, se reduce a algunas pequeñas hojas y lascas de sílex, un discoide de pizarra desbastado - presumiblemente usado como tapadera de una orza- y un segmento de círculo microlítico de sílex de sección triangular y dorso tallado con retoque abrupto.

Las unidades de habitación correspondientes a esta primera ocupación son prácticamente desconocidas. Sólo en el Corte «B. IV» pudo documentarse la presencia de una estructura delimitada por una alineación paracircular de bloques de granito hincados que dejan en su trazado una zona libre en la que se registró lo que bien pudiera haber constituido un agujero para la inserción de un poste $y$, frente a el, y al exterior, una pequeña placa circular de barro cocido. Podría sugerirse su condición de hogar anexo a la cabaña, pero la falta de indicios de combustión impide asegurar esta posible identificación funcional (Fig. 4).

La práctica totalidad de los materiales brindados por este Corte, proceden del interior de esta estructura, delimitada, como se adelantó, por una alineación de piedras que, más que un zócalo o basamento, parece constituir una especie de refuerzo de base o contención de otra posible construcción erigida con materiales perecederos. La presencia de abundantes pellas de barro con improntas vegetales - de cañas y retama - induce a considerar la construcción de un frágil chamizo vegetal probablemente enlucido - y aislado- con barro.

$\mathrm{Al}$ igual que esta habitación, según se indicó, la ocupación neolítica del Cerro - por el momento, sólo documentada en su base- se halló fosilizada por una capa de árido completamente estéril.

\section{El Calcolítico (Fig. 5)}

La ocupación de este sitio, particularmente en la parte superior o meseta, permite - según la presencia/ausencia de algunos elementos (p.e. campaniforme, cobre... etc.) - delimitar provisionalmente al menos dos fases, si bien entre ambas se advierte una notable afinidad ergológica, expresión 

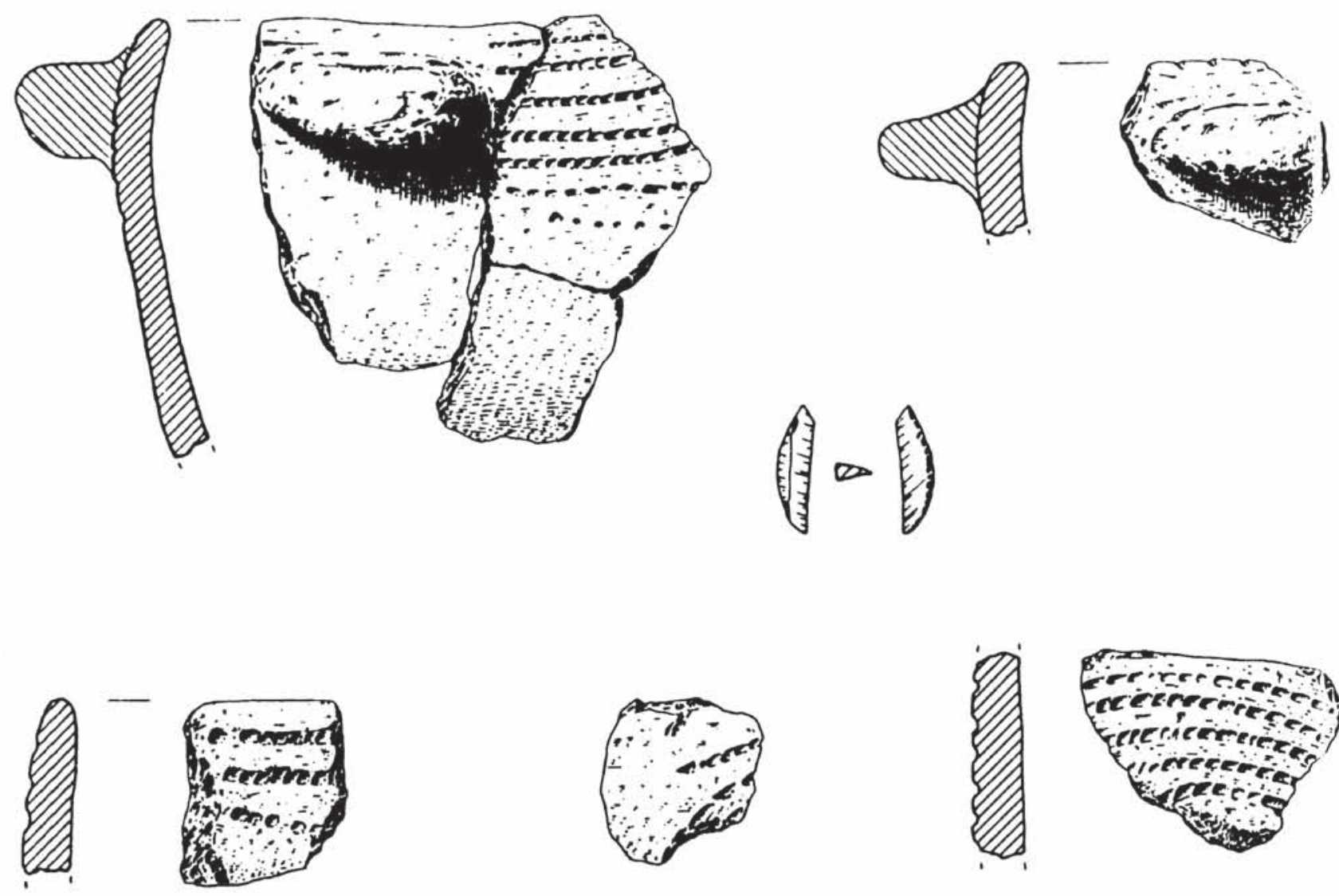

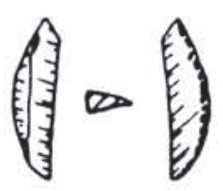
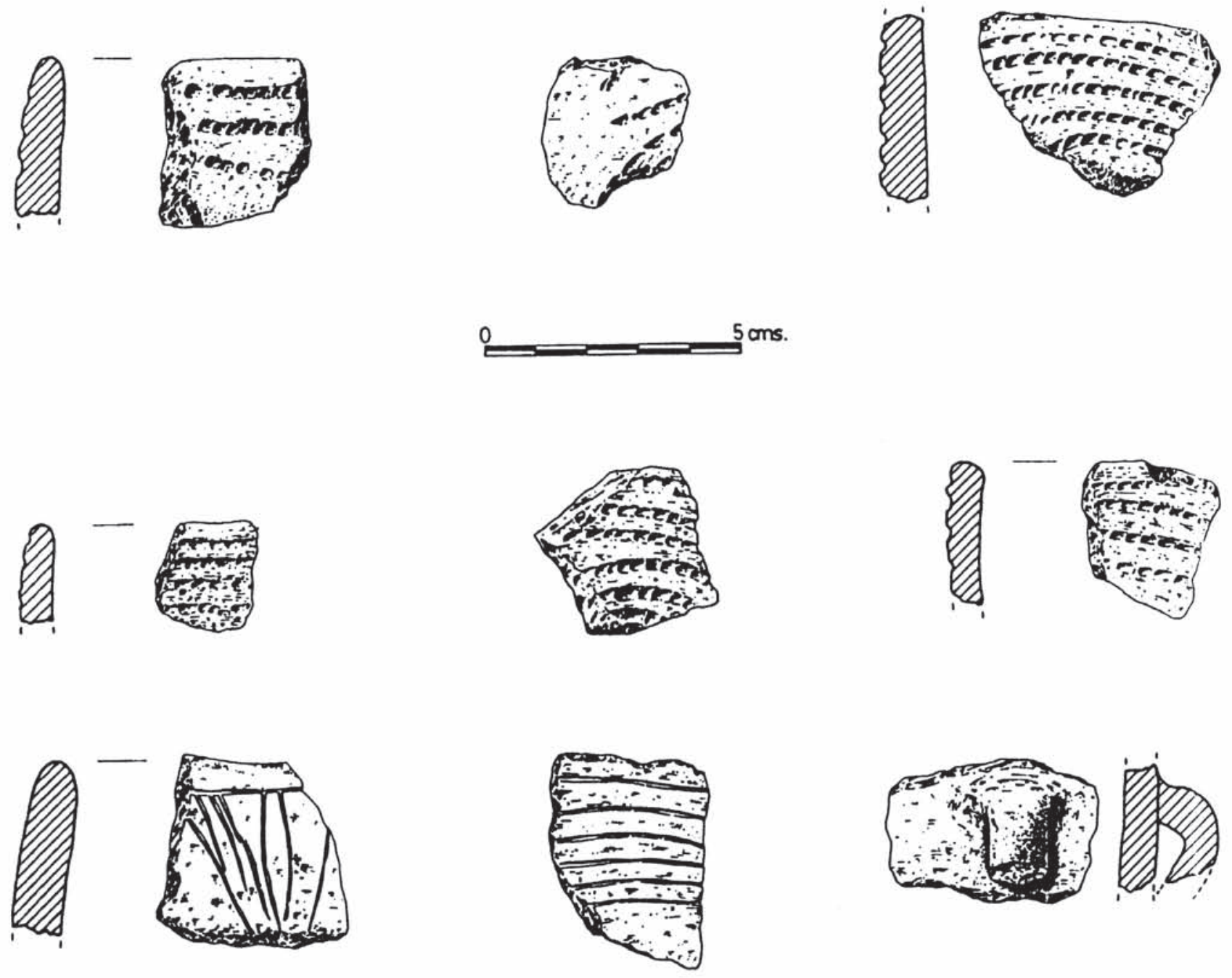

FIG. 3.- Materiales cerámicos correspondientes a la fase neolítica (CH. 1) del yacimiento. 

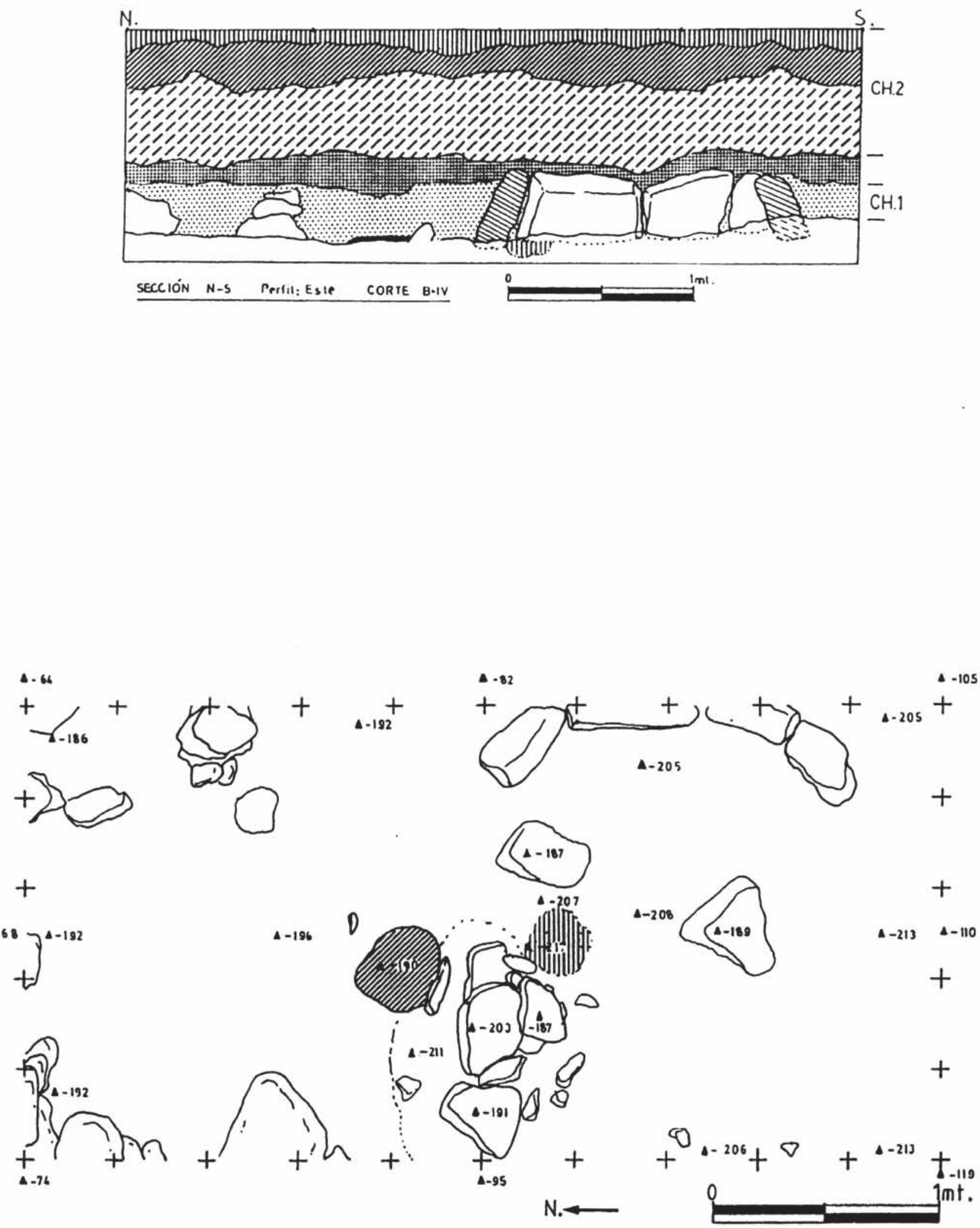

Planimetria del corte: B-IV

Fig. 4.- Perfil estratigráfico del corte B. 4 y plano del mismo correspondiente a la capa inferior, neolítica. 

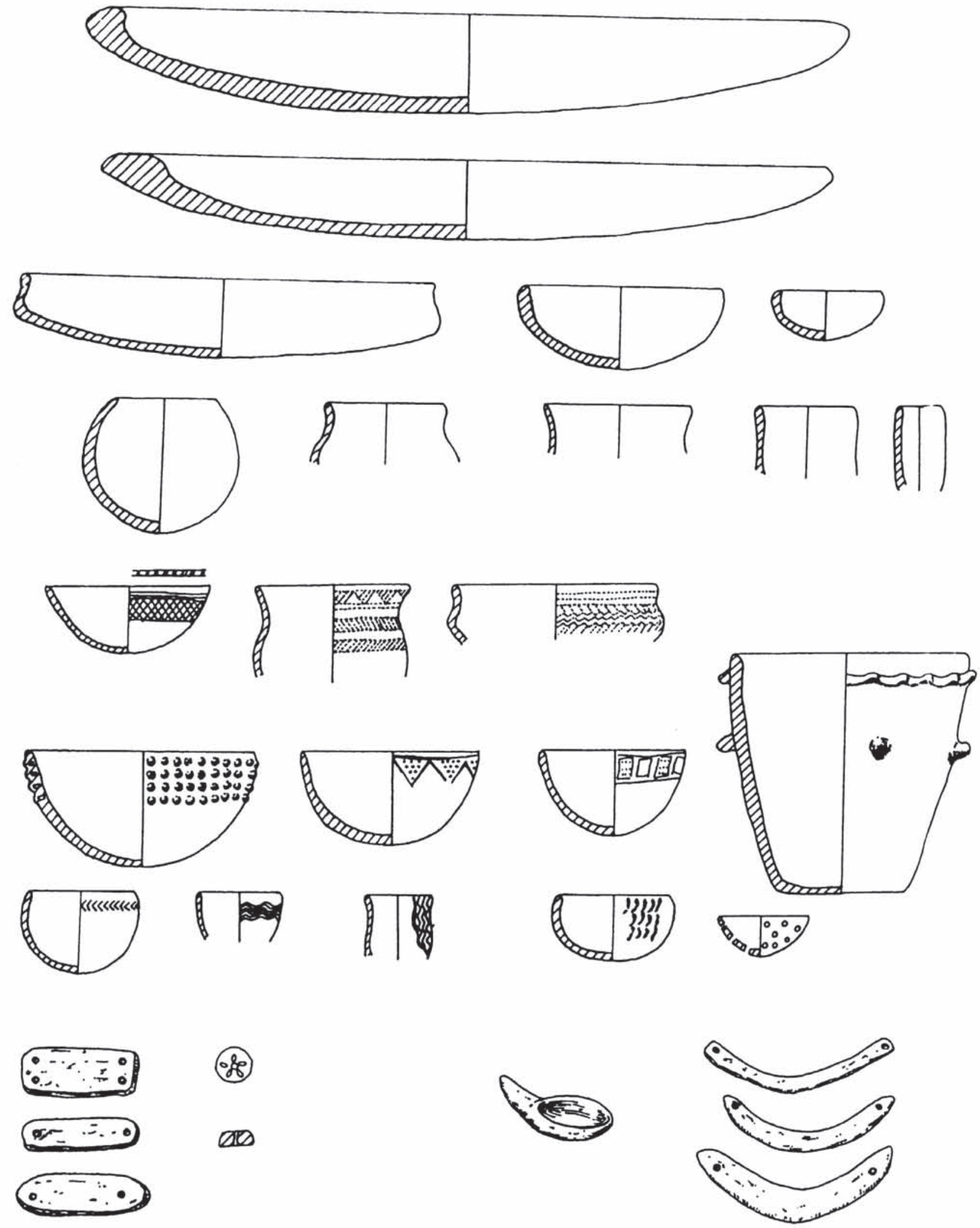

Fig. 5.- Esquemas formales y decorativos de las cerámicas más representativas del desarrollo calcolítico del yacimiento ( $\mathrm{CH}$. 2). 
de una continuidad cultural y de poblamiento. En relación con esta se hallan numerosos sitios localizados en las inmediaciones del yacimiento, sólo reconocidos de forma superficial.

La diferenciación sugerida a nivel ergológico no resulta tan clara desde el punto de vista estratigráfico; únicamente es perceptible un cambio gradual de la coloración del paquete, más ceniciento y compactado cuanto mayor es su profundidad. Ello, probablemente explicita la cohesión cultural de una misma comunidad afincada en esta localidad durante la Edad del Cobre. De ahí que procedamos al examen conjunto de sus vestigios para, posteriormente, discutir su posible evolución desde la óptica de sus aspectos más significativos.

Entre unas cotas medias de 0,4-0,9 m. de profundidad se advierte una capa cenicienta y compactada con abundantes restos. La cerámica muestra un claro predominio de recipientes semiesféricos, en su mayoría cuencos, de mediano y pequeño tamaño; de platos, fuentes y cazuelas, preferentemente los provistos de bordes engrosados-reforzados, y en menor medida, de bordes engrosados-almendrados y de "pestaña" (Ruiz Mata, 1975) entrante, junto a ejemplares simples y escudillas plano-cóncavas de bordes redondeados. Además de ello, se constatan algunas ollas correspondientes a tipos globulares, ocasionalmente con bordes engrosados-reforzados. Junto a algunos fragmentos de vasos, se cuenta un interesante conjunto de pequeñas tazas de superficies oscuras, bien alisadas (casi bruñidas) asimilables a los ejemplares denominados "de paredes finas" (Hurtado, 1986; 1987).

La cerámica decorada es relativamente abundante, asociándose en su mayoría a vasijas abiertas, ya que el grupo de ollas sólo presenta algunas acanaladuras someras alrededor de la boca o, caso de poseer cuello, con decoración de cordones impresos como elemento diferenciador. Precisamente es el conjunto de decoraciones impresas el que, asociado a la incisión como técnica de delimitación de los campos (triangulares o rectangulares), resulta más característico, contándose matrices realizadas con punzón de punta roma circular y triangular, rellenas con pasta blanca. Aparte de ello, se registran estas mismas técnicas distribuidas sobre el cuerpo de los vasos - en su mayoría cuencosasí como impresiones de caña, también organizadas en bandas.

De entre este lote cerámico, aparte de un esteliforme inciso, relativamente frecuente en sitios calcolíticos -mas cuyos precedentes se remontan hasta el Neolítico "medio"-, otros elementos definidores de esta capa son las cerámicas incisas y un fragmento pintado. Las primeras, con triángulos, series de líneas perpendiculares al borde, trazos someros oblícuos y entrecruzados alrededor del borde, así como diseños en forma de espina de pescado; el segundo, con series de trazos rojos incurvados superpuestos constituyendo motivos arracimados a partir de la boca.

Los mamelones - perforados o no- como elementos de prehensión, y los crecientes, pesas y fusayolas, además de un probable morillo, entre la "cerámica industrial", completan el registro cerámico hallado en esta capa.

La industria lítica es abundante, siendo relativamente variada la representación de útiles tallados y pulidos, así como de instrumentos de trituración y molienda. Entre la primera destaca el elevado índice de foliáceos y hojas de sección triangular y trapezoidal. Aparte de algunas lascas, por lo general grandes y de secciones espesas, este instrumental resulta definido por la relativa diversidad de armaduras, contándose foliáceos de base recta o plana, de base convexa -cordiformes y alargadas-, triangulares de bordes rectos y, finalmente, puntas de flecha de base cóncava. Aparte de estas, se cuenta una armadura romboidal con pequeños apéndices laterales y varios ejemplares con aletas.

La ultima fase de ocupación del yacimiento se desarrolla desde superficie hasta los $0,4 \mathrm{~m}$. de profundidad media. La capa superficial, de unos $15-20 \mathrm{cms}$. de potencia, se encuentra muy removida por las labores agrícolas, observándose un brusco cambio de textura y coloración de la tierra en la zona de contacto con el primer nivel no alterado de este yacimiento.

Es esta una capa muy rica en hallazgos, cuyas características ergológicas son muy similares a las ya descritas en la anterior unidad estratigráfica. Sin embargo, como ya se adelantó, determinados materiales permiten dotar a los niveles superiores del Cerro de la Horca de personalidad propia.

Lo más destacable, por su significación intrínseca, es la presencia de cerámicas campaniformes y de algunos elementos metálicos. Entre las primeras, la nota de mayor interés la pone, sin duda, la 
documentación de ejemplares de los cuatro tipos principales de los campaniformes peninsulares: especies incisas, puntilladas geométricas, maritimas $\mathrm{y}$ cordadas - un solo fragmento- están representadas en el Cerro de la Horca, sin que, por desgracia, sea posible por el momento nada más que constatar su presencia, ya que su aparición se produce generalmente en las capas más altas del yacimiento, donde se ha perdido cualquier posible relación estratigráfica debido a la acción continuada de los arados.

Junto con las cerámicas campaniformes, la aparición de algunos punzones de cobre biapuntados y láminas enrolladas del mismo metal confirman la localización de este paquete estratigráfico en un momento pleno del desarrollo calcolítico de esta región. Pese a la incertidumbre que supone la alteración de estos niveles, quizás haya que relacionar con campaniformes y cobre la aparición de algunos ejemplares de cerámica decorada con pastillas repujadas o aplicadas. Su vinculación con campaniformes cordados ha quedado de manifiesto en los resultados obtenidos en otros yacimientos de la zona (Hurtado y Amores, 1982), aunque continúa abierta la polémica sobre el origen y difusión de tales elementos. Las condiciones de su hallazgo en el Cerro de la Horca no permiten, de ningún modo, aportar nuevos datos sobre el particular.

En todo caso, parece clara una desaparición gradual de campaniformes y pastillas repujadas conforme se avanza en profundidad, en favor de los diseños en espina de pez, triangulos incisos, etc., que ya se describian en la unidad estratigráfica anterior.

En la zona alta del Cerro se documentaron, en este nivel, los restos de dos estructuras de habitación, prácticamente superpuestas. La primera de ellas conservaba dos hiladas de bloques de granito de pequeño tamaño calzados con guijarros. Bajo ella se desarrollaba otra estructura muy similar, que mantenía aún tres hiladas de bloques de granito de mayor tamaño y de disposición más irregular que en el primer caso.

Ninguna de las dos estructuras conserva su planta íntegra, aunque las trayectorias de los muros conservados permite el reconocimiento de plantas aproximadamente ovales. Sobre estas bases de mampostería se desarrollarían paramentos construidos con elementos vegetales trabados con barro, a juzgar por las numerosas pellas de arcilla con impresiones de ramas y cañas que pudieron recogerse. Estas construcciones fueron, además, reforzadas con postes de madera, clavados en la tierra y calzados en su cimentación con pequeñas lajas de pizarra.

\section{IDENTIFICACION CULTURAL}

El interés del asentamiento del Cerro de la Horca estriba no sólo en su localización geográfica, sino, sobre todo, en la posibilidad que ofrece de apuntar - siquiera de forma preliminar- una caracterización del desarrollo de la Edad del Cobre en este territorio. En el primero de los sentidos, su ubicación en la cabecera del río Tamuja, afluente del Tajo, permite relacionarlo con la dinámica cultural por el momento registrada en diversos tramos de esta última cuenca fluvial. Así, independientemente de mayores precisiones, es clara su vinculación con el yacimiento de Los Castillos de Las Herencias en Toledo (Alvaro et alii, 1986) y, por extensión, con una serie ya relativamente amplia de habitats calcolíticos de la orla occidental de la Meseta Norte. Por otra parte, participa igualmente de bastantes de los rasgos advertidos en el poblamiento de la Cuenca Media del Guadiana, principal referencia de tipo secuencial, por el momento constatada, sobre el poblamiento calcolítico en Extremadura. (Enríquez-Hurtado, 1986).

Por otra parte, su registro estratigráfico constituye la primera referencia explícita acerca del proceso evolutivo de la Edad del Cobre en esta zona de Extremadura. Desafortunadamente, este desarrollo parece corresponderse en líneas generales con una fase ya plena y tardía del Calcolítico, faltando toda evidencia relativa a un horizonte previo de formación. En relación con ello, cabe valorar la discontinuidad de la estratigrafía, en cuya base se sitúa un interesante nivel definido por sus cerámicas decoradas e industria con algún geométrico, de clara filiación neolítica. El interés que 
este descubrimiento reviste para el estudio del Neolítico de las tierras del interior de la Península se ve, no obstante, mermado, ante la imposibilidad de determinar cualquier nexo entre el mismo y los inicios de las primeras culturas metalúrgicas de la región.

Los datos recientemente brindados por la excavación de la cueva de La Charneca, con especies cerámicas lisas y, sobre todo, decoradas (Enríquez, 1986), muy semejantes a las aquí tratadas, en lo que se refiere a la fase neolítica del yacimiento, obliga a discutir la asignación cultural de este horizonte tardoneolítico en el contexto de la prehistoria reciente del Suroeste peninsular. En relación con ello, se halla no sólo la identificación de este horizonte, sino la propia periodización de la Edad del Cobre en estos territorios.

Evidentemente, la ocupación neolítica del Cerro de la Horca aparece caracterizada por la asociación de al menos dos elementos que no van a perdurar en las etapas calcolíticas subsiguientes: la cerámica decorada con técnica de boquique - tradicionalmente polémica- y una industria microlítica, aquí al menos singularizada por un segmento de círculo (1).

La cerámica de boquique, aparte de la cueva homónima (Almagro, 1977; Rivero, 1972-73), se localiza en numerosas estaciones, habiéndose registrado recientemente en las inéditas de Atambores (Zarza de Montánchez), Peña Aguilera (Montánchez), Los Barruecos (Malpartida de Cáceres), Cueva de Conejar (Cáceres), Alardos (Madrigal de la Vera) y La Oliva (Plasencia). La Meseta Central presenta un número más reducido de yacimientos en los que esta técnica hace acto de presencia, documentándose con certeza hasta el momento en Verdelpino (Cuenca) (Moure y FernándezMiranda, 1977), Cuevas de La Nogalera (Municio y Ruiz-Gálvez, 1986) y de La Vaquera (Zamora, 1976), en Segovia, y en la Galería del Sílex (Atapuerca, Burgos) (Apellániz y Domingo, 1987). Pese a lo precario de estos datos, referidos a zonas actualmente en estudio, parece evidente una cierta rarificación de estas especies conforme nos alejamos de tierras extremeñas.

En cuanto al segundo elemento, la industria microlítica, pese a su infima representación en Plasenzuela, es interesante señalar por una parte, su inexistencia durante la ocupación calcolítica del sitio -en sintonía con lo advertido en el poblamiento de la Cuenca Media del Guadiana- y, por otra, su generalizada presencia en los sepulcros megalíticos adintelados que pueblan este territorio (Bueno, 1987: 82). Sin embargo, el problema de los geométricos en Extremadura suele interpretarse como una pervivencia neolitizante durante la Edad del Cobre, incluso en una fase ya plena (Enriquez y Hurtado, 1986: 40; Hurtado, 1987: 40).

En esta región, el grueso de la información procede de una serie de yacimientos localizados sobre la Cuenca Media del Guadiana. Así, por ejemplo, los de Araya (Enríquez, 1982), El Lobo (Molina, 1980) y, sobre todo, La Pijotilla (Hurtado, 1987), entre otras localizaciones próximas a Badajoz (Enríquez y Domínguez, 1984), o las registradas en la comarca de Llerena (Enríquez e Iniesta, 1985). Sobre esta base se plantea una secuencia cultural trifásica (Hurtado, 1986, 1987; Enríquez y Hurtado, 1986) afín a las líneas maestras de la dictada para el Bajo Alentejo y Algarve (Tavares y Soares, 1977 y 1981) que, asimismo, parece proyectarse sobre Huelva (Martín de la Cruz, 1986) y el Bajo Guadalquivir (Fernández y Oliva, 1986).

Desde esta perspectiva, la secuencia cultural de la Edad del Cobre en Extremadura contemplaría un desarrollo trifásico. La fase más antigua, definida por el "horizonte de la cazuela carenada" -aún sin platos de "borde almendrado"-, con presencia de algunas cerámicas decoradas, de armaduras de base cóncava e inexistencia de vestigios de cobre, tipificada por localidades abiertas como la de Araya, se ha venido asimilando, _un tanto ambiguamente-, a un Neolítico Final contemporáneo al Calcolítico Inicial o, más bien, a un Calcolítico Inicial, por consiguiente, neolitizante.

(1) El hallazgo de este tipo de elementos en contextos habitacionales, es tan infrecuente como numéricamente escaso, circunstancia que induce a ponderar su posible correlación con contextos funerarios contemporáneos, caso de las estructuras megalíticas arquitrabadas, tan abundantes en este territorio. A título orientativo, pueden reseñarse los, ciertamente escasos, ejemplares de geométricos hallados en estaciones como La Peña de Los Gitanos, durante la fase Montefrío I, estrato VI N/A, en Granada, (Arribas-Molina 1978: 118) así como el también trapezoidal correspondiente al inicio de la ocupación (estrato II, sector A, estructura 3) del poblado onubense de Papa Uvas, fase I, (Martín de la Cruz, 1985: 149). 
El Calcolítico Pleno cuenta con dos horizontes: uno más antiguo, o arcaizante, protagonizado por localidades como El Lobo o la Granja Céspedes - ambos de filiación «dolménican-, al que sucede sin solución de continuidad otro atestiguado por La Pijotilla. Esta fase, considerada en su conjunto, se correspondería con una diversificación tipológica de los asentamientos, acorde probablemente con una estrategia de control geoeconómico del territorio. En este sentido, El Lobo (Calcolítico Pleno «arcaizantew) revelaría la existencia de poblados abiertos sujetos a una triple influencia: por una parte, la del horizonte del Calcolítico Inicial, patente a través de la presencia de cazuelas carenadas y decoraciones impresas y brunidas; por otra, la tipificada por La Pijotilla, expresada por el hallazgo de platos de borde almendrado y utensilios de cobre; finalmente, la aparición de idolosplaca y báculos decorados - como en la Granja de Céspedes- inducen a considerar no sólo el carácter megalítico de estas poblaciones, sino también la asimilación a este momento del Calcolítico Pleno del grueso de los sepulcros de cámara poligonal y corredor de Extremadura.

Por último, La Pijotilla (Calcolítico Pleno y Final) se desarrollaría paralelamente a la utilización de El Lobo, deduciéndose al menos tres fases para su ocupación (Hurtado, 1986; 1987). La primera de ellas (III)a), estaría caracterizada por la abundancia de platos y de ollas, contándose sólo algunas cazuelas carenadas. La segunda (IIIb) -posiblemente contemporánea del campaniforme en el Estuario del Tajo- mostraría la presencia de elementos como las pastillas repujadas, las decoraciones esteliformes - presentes en Araya-, las peinadas onduladas, —situables en un ambiente precampaniforme, en los primeros compases de la Edad del Cobre peninsular, como mostrarían los hallazgos de Vila Nova de San Pedro y Penedo, en Portugal, y de Las Pozas, en Zamora (Del Val, 1983: 78)_y los "vasos de paredes finas". Por último, la tercera (IIIc), ya muy desvirtuada, se correspondería con especies campaniformes y, posiblemente, con la edificación de casas rectangulares de piedra.

Al hilo de ello, el seguimiento estratigráfico de los "vasos de paredes finas", es sumamente sugestivo, ya que, tras la evidencia del enterramiento circular cistoide de La Guadajira (Hurtado, 1985), constituye una sólida aportación acerca de las bases autóctonas de la Edad del Bronce de la zona, día a día más antiguo (Ruiz-Gálvez, 1984).

Desde esta óptica, El Cerro de la Horca podría asimilarse sin dificultad al desarrollo ocupacional de La Pijotilla, del mismo modo que su etapa tardoneolítica es asimilable a los vestigios recuperados en la Cueva de la Charneca. Sin embargo, cabría discutir este esquema y, con ello, precisar la adscripción cultural y cronológica del yacimiento de Plasenzuela. Distintas evidencias lo aconsejan.

El examen del conjunto de materiales entregados por esta localidad muestra de forma ostensible las diferencias existentes entre el equipamiento doméstico de la frecuentación inicial $(\mathrm{CH} .1)$ y el usado durante la Edad del Cobre (CH. 2). Desafortunadamente, se produce, como se adelantó, un hiatus. Esta inferencia, a su vez resulta constrastada por el propio registro de área superior, o meseta. Además, la diferente distribución espacial de ambas ocupaciones es un aspecto que no conviene obviar: mientras los vestigios de $\mathrm{CH}$. 1 se registran en la base de este cerro, los pertenecientes a la Edad del Cobre (CH. 2) se agrupan preferentemente en la cúspide amesetada del mismo. Inferir de ello la posible transformación de los patrones de ocupación, a través del reacondicionamiento del habitat y su adecuación a condiciones defensivas, ante la falta de evidencias correspondientes a momentos intermedios, es sólo una hipótesis.

Con todo, estas diferencias - trasunto de un uso bien distinto del Cerro y, acaso también, de la diferente dedicación económica de sus ocupantes- parecen obedecer a la distancia cronológica existente entre ambas utilizaciones del yacimiento.

Como se ha razonado, $\mathrm{CH}$. 1 y las restantes localidades anteriormente reseñadas en las que se han registrado fragmentos con decoración de técnica de boquique, presentan una estrecha afinidad con la ocupación inicial de La Charneca, cavidad situada en las inmediaciones de Oliva de Mérida, atribuida preliminarmente "al Neolítico Final o, en su defecto, a un Calcolítico muy arcaizante" (Enríquez, 1986: 21) y, por consiguiente, dentro de un ámbito relativo a los orígenes de La Edad del Cobre, por el momento tipificado por asentamientos neolitizantes como el de Araya. Así pues, junto a la posible obsolescencia de este tipo de localidades, asimilables sin dificultad al «horizonte da taça carenada" del S.O., se encontraría este complejo caracterizado por las decoraciones de punto-y-raya, 
presuntamente contemporáneo del desarrollo de las primeras comunidades propiamente calcoliticas en la Baja Extremadura. Por ello entre otros aspectos, creemos acertada la atribución del conjunto de materiales de La Charneca - siquiera genéricamente - al Neolítico, en particular a una fase avanzada (Enríquez, 1986: 23), no al Neolítico Final caracterizado por las cerámicas lisas — «horizonte de la taça carenada»- y, desde luego, tampoco a los inicios de La Edad del Cobre, mudándolas "arcaizantes». Desde esta óptica, esta ocupación inicial del Cerro de La Horca -al igual que la de La Cueva de La Charneca- parece corresponderse con el epigono de la tradición neolítica definida por las cerámicas decoradas, siendo factible asimilarla al denominado Neolítico "Tardíon de la Alta Andalucía (Arribas y Molina, 1980: 12) o al "Superior" del Occidente portugués (Guilaine y Veiga Ferreira, 1970).

Los materiales con decoración de boquique de La Cueva de la Charneca, al igual que los de esta primera ocupación del Cerro de La Horca y los de las restantes localidades señaladas (cuevas, abrigos y estaciones abiertas), pueden asimilarse sin dificultad a esta fase tardeoneolítica y, con ello, a un fondo cultural neolítico, previo a Neolítico Final de Cerámicas lisas, en el S.O. caracterizado por la «taça" o cazuela carenada, base, a su vez, del desarrollo de La Edad del Cobre en estos territorios (Piñón, 1987b).

A lo largo de la secuencia cultural del Neolítico a La Edad del Bronce, al menos en el ángulo sudoccidental de la Península, resultan claramente definidos dos segmentos, ambos parcialmente representados en este yacimiento. Uno, propiamente neolítico, que, independientemente de la filiación de su génesis (cardial o "acardial") se desenvuelve hasta alcanzar una fase Tardia, y otro, a partir del Neolítico Final, que, sin solución de continuidad, actúa como sustrato del ulterior desarrollo del calcolítico, base que, a su vez, generará las transformaciones de la denominada Edad del Bronce. A caballo del desarrollo de ambos segmentos, se sitúa el correspondiente al megalitismo, fenómeno ciertamente polimórfico en el que, si bien se reconocen una serie de fases (Leisner, 1966; Cunha Serrao, 1979), continua siendo arriesgado advertir una evolución (Kalb, 1981). A lo largo de su desarrollo, empero, se advierten algunas de sus líneas de fuerza (Oliveira Jorge, 1983), y dos tradiciones constructivas - la adintelada y el sistema abovedado- propios también de sendas "áreas focales" entre las que, presumiblemente, debieron mediar ciertos contactos, primero (Leiner, 1951; Ferrer Palma, 1982) de Oeste a Este y, después, en dirección opuesta.

De los contactos de los constructores de sepulcros adintelados con las poblaciones de la "taça carenada", con antelación a las primeras aportaciones milláricas en Occidente, son prueba evidente (Piñón, 1987a) los hallazgos de ídolos - y, acaso también, de foliáceos- en localidades como El Lobo, La Granja de Céspedes o Papa Uvas. De las relaciones - posiblemente expansión- de estas comunidades dolménicas hacia el Este, Occidente posee la evidencia suministrada por los «ídolos almerienses" ofrendados en diversas tumbas del IV milenio B.C., las estelas antropomorfas recientemente descubiertas en dos de los monumentos "compuestos" de la necrópolis de El Pozuelo, en Huelva, y finalmente, aparte de algunos testimonios rupestres, el sincretismo iconográfico -y presumiblemente iconológico- de placas como las de Genemigo (Viana-Dias de Deus, 1955: 54) o Lapa do Bugio, sepultura 11 (Monteiro et alii, 1971: 117).

En apoyo tanto de aquellos contactos como de estas relaciones y, en definitiva, de la contemporaneidad del Neolítico Final definido por el «horizonte de la taça carenada" y los constructores de dólmenes (cámara poligonal alentejana, fase compuesta del megalitismo en Huelva) cabe advertir una serie de datos recientes. Por una parte, la "fundación» del propio yacimiento de Los Millares en una fase plena de la Edad del Cobre del S.E. o, más explícitamente, en un momento avanzado de la misma (Arribas-Molina, 1988: 5). Por consiguiente, el complejo de Los Millares -como los de Valencina de la Concepción (Fernández y Oliva, 1985) o La Pijotilla (Hurtado y Amores, 1982) en el S.O. no es la causa de un proceso, sino su consecuencia. De ahí que, lógicamente, el conjunto de elementos catalogados como "coloniales" o "milláricos" (fortificaciones, sepulcros abovedados, incluso objetos de cobre... etc.) en Occidente se detecten preferentemente a partir del Calcolítico Pleno, sin campaniforme. La segunda evidencia ès la brindada conjuntamente por la reinterpretación estratigráfica del asentamiento de Paredes (Cunha Serrao, 1983) y la utilización funeraria de la Gruta de 
Feteira (Zilhao, 1984). Ambas localidades muestran nitidamente la diferenciación del Neolítico Final de cerámicas lisas respecto al fondo cultural tardoneolitico previo (Neolítico Tardio) y la Edad del Cobre. Según ello, el horizonte de los "copos canelados" del calcolítico inicial extremeño (MarquesCunha Serrao, 1979), dejaría de prescribir la atribución transicional preliminarmente otorgada al "horizonte» Vale Pincel II-Cabeço da Mina en el Bajo Alentejo y Algarve, y, por extensión, la del conjunto de asentamientos atribuidos a un Calcolítico Inicial "neolitizante" o "arcaizante" de las restantes regiones del S.O. Tanto la datación radiocarbónica de Lapa do Fumo, B. $(3.090 \bumpeq 160$ b.C.; Cunha Serrao-Marques, 1987) como la de Papa Uvas, II (2.890 $\bumpeq 120$; Martín de la Cruz, 1985), entre otras, una vez calibradas - como corresponde - resultan notablemente más antiguas que las poseidas para el Calcolítico Inicial del Estuario del Tajo (Whittle-Arnaud, 1975), y ajustadas, en cambio, a las brindadas por distintas cámaras poligonales correspondientes a la fase de apogeo del megalitismo occidental (Leisner, 1966; Cunha Serrao, 1979).

Una última sugerencia de esta reflexión subrayaria la presencia de cazuelas carenadas en distintos sitios como Vale Pincel II, Papa Uvas II-III o Araya y, por el contrario, de platos de borde engrosado en Alcalar, Valencina de la Concepción (Corte ${ }^{*} \mathrm{C} m$ ) o La Pijotilla. Como recientemente se ha planteado (Hurtado, 1987) este desarrollo en el S.O. se caracterizaria por presentar dos elementos definidores: la "taça" o cazuela carenada, inicialmente atribuida a la transición del Neolítico Final a la. Edad del Cobre (Tavares-Soares, 1977) no, como se ha indicado, a un Calcolítico neolitizante, y el plato de borde almendrado, habitualmente considerado exponente de un momento Pleno de esta última (Ruiz Mata, 1975). Sin embargo, según el diseño secuencial aquí sugerido, entre Araya (Neolítico Final) y La Pijotilla (Calcolítico Pleno y Final) ciertamente se hace evidente la falta de una auténtica «transición» u horizonte de formación de esta plenitud de la Edad del Cobre. Esta, caracterizada por la asociación estratigráfica de sendos elementos definidores del Neolítico Final — «taça" carenada - y del Calcolítico Pleno del S.O. —plato de borde engrosado-, es la atestiguada por Papa Uvas IV, (Martín de la Cruz, 1986b), y las instalaciones previas a la fortificación de Los Vientos I (Piñón, 1988) y Monte da Tumba I (Tavares da Silva-Soares, 1985), correspondientes al Calcolítico Inicial, fase en la Cuenca Media del Guadiana probablemente atestiguada por sitios como El Lobo (Molina, 1980) y algunas otras localidades de su entorno (Enríquez e Iniesta, 1984).

Desde esta óptica, la ocupación del Cerro de La Horca, mostraría - al menos según los materiales recuperados- su correspondencia con el Neolítico Tardío $(\mathrm{CH} .1)$ así como con las fases ya Plenas y Finales del desarrollo de La Edad del Cobre (CH. 2) en estos territorios. Debido a ello, acaso se verificó la utilización de la parte superior de este batolito, defendida de forma natural y desde la que se veía asegurado el control de los pasos y de los campos inmediatos. Como se ha razonado, faltan por el momento las evidencias relativas precisamente a los horizontes de formación de este desarrollo calcolítico (Neolítico Final y Calcolítico Inicial o Antiguo-, por lo que resultaria aventurado arriesgar mayor número de hipótesis sobre las características del proceso bosquejado en estas páginas, cuyo objeto no es otro que razonar el interés de esta región y, en particular, de este asentamiento para la definición del poblamiento de la Alta Extremadura durante la Edad del Cobre. La caracterización pormenorizada de su uso así como la explicación de este proceso, pretenden efectuarse en otra ocasión. 


\section{BIBLIOGRAFIA}

Almagro Gorbea, M. (1977): "El Bronce Final y el Periodo Orientalizante en Extremadura». Bibliotheca Praehistorica Hispana, XIV. Madrid.

Alvaro, E.; Municio. L. y PiÑón. F. (1985): "Informe sobre el yacimiento de "Los Castillos" (Las Herencias, Toledo): un asentamiento calcolítico en la Submeseta Sur». I Congreso de Historia de Castilla-La Mancha (Toledo, 1985). En prensa.

ApellániZ, J. M.; Domingo. S. (1987): «Estudios sobre Atapuerca (Burgos). II. Los materiales de superficie del Santuario de la Galería del Sílexw. Cuadernos de Arqueologia de Deusto, 10. Bilbao.

Arribas, A. y Molina, F. (1978): «El poblado de Los Castillejos en Las Peñas de los Gitanos (Montefrío, Granada)». Cuadernos de Prehistoria de la Universidad de Granada. Serie Monográfica, 1. Granada.

- (1980): "El poblado de Los Castillejos de Montefrio (Granada)". En M. Ryan (ed.): "The origins of Metallurgy in Atlantic Europen (V Atlantic Colloquium): 7-34. Dublin.

- (1988): "Los inicios de la metalurgia y el desarrollo de las comunidades del S.O. de la Península Ibérica durante la Edad del Cobre. Los Millares Santa Fe de Mondújar, Almería)». Primeras Jornadas de Arqueología Andaluza, Sevilla, enero de 1988. Folios mecanografiados.

Bueno Ramírez, P. (1987): «Megalitismo en Extremadura: estado de la cuestión». "El megalitismo en la Península Ibéricas: 73-84. Madrid.

CUNHA SERRAO, E. DA (1979): «Sobre a peridizaçao do Neolítico e o Calcolítico do territorio portugues». Actas da 1 Mesa Redonda sobre o Neolitico e o Calcolitico em Portugal. Trabalhos do G.E.A.P., 3: 147-182. Porto.

- (1983): «A estaçao prehistórica de Parede. Documentos ineditos sobre a estratigrafía e estructuras (Campanha de 1956). O Arqueologo Portugues, I, serie IV: 119-147. Lisboa.

EnRíuez Navascues, J. J. (1982): "Avance al estudio de los materiales procedentes de Araya. Mérida (Badajoz)". Pyrenae, 17-18: 191-203. Barcelona.

- (1986): "Excavación de urgencia en la Cueva de La Charneca (Oliva de Mérida. Badajoz)». Noticiario Arqueológico Hispánico, 28: 7-24. Madrid.

Enriouez J. J.; Domínguez, C. (1984): «Yacimientos pre y protohistóricos de Badajoz y sus alrededores». Revista de Estudios Extremeños, XXXIX, 1. Badajoz.

Enríquez J. J.; Hurtado, V. (1986): "Prehistoria y Protohistoria». En "Historia de la Baja Extremadura»: 3-50. Badajoz.

ENRÍQUeZ J. J.; INIESTA, J. (1985): "Notas sobre los poblados calcolíticos de la comarca de Llerena». Homenaje a J. Cánovas Pesini. Badajoz.

FERNÁNDEZ, F.; OlIVA, D. (1985): "Excavaciones en el yacimiento calcolítico de Valencina de la Concepción (Sevilla). El Corte D ("La Perrera")". Noticiario Arqueológico Hispánico, 25: 9-13. Madrid.

Ferrer Palma, J. E. (1982): «Consideraciones generales sobre el megalitismo en Andalucía». Baetica, 5: $121-132$. Málaga.

Guillaine, J.; Vega Ferreira, O. DA. (1970): «Le Neolithique ancien au Portugal». B.S.P.F., 67. 1: 304-332. París.

Hurtado, V. (1985): "Excavación de una tumba circular de la Edad del Bronce en Guadajira (Badajoz)». Homenaje a J. Cánovas Pesini. Badajoz.

- (1986): «El Calcolítico en la Cuenca Media del Guadiana y la necrópolis de La Pijotillan. Actas de la Mesa Redonda sobre Megalitismo Peninsular (Madrid, 1984). Boletín de la A.E.A.A., 20: 51-75. Madrid.

- (1987): «El megalitismo en el Suroeste peninsular: problemática en la periodización regional». El Megalitismo en la Península Ibérica: 31-43. Madrid.

Hurtado, V.; Amores, F. (1982): «Relaciones culturales entre el Sudeste francés y La Pijotilla (Badajoz) en el Calcolítico: Las pastillas repujadas y el campaniforme cordadow. Habis, 13. Sevilla.

KALB, PH. (1981): «Zur relativen chronologie das portuguesis megalithgrabern». Madrider Mitteilungen, $22:$ 55-77. Heidelberg.

LEISNER, G. y V. (1951): «Antas do Concelho de Requengos de Monsara». Lisboa.

- (1966): «Die verschicheren phasen das Neolithikums im Portugal». Paleohistoria, 12: 363-372. Groningen.

Marques, J. L.; Cunha Serrao, E. (1979): "O povoado calcolítico do Alto do Dafundo". Actas da 1 Mesa Redonda sobre o Neolitico e o Calcolitico em Portugal. Trabalhos do G.E.A.P., 3: 121-133. Porto.

Martín de la Cruz, J. C. (1985): "Papa Uvas I. Aljaraque, Huelva. Campañas de 1976 a 1979 . Excavaciones Arqueológicas en España, 136. Madrid.

- (1986a): „Papa Uvas II. Aljaraque, Huelva. Campañas de 1981 a 1983». Excavaciones Arqueológicas en España, 149. Madrid.

- (1986b): *Aproximación a la secuencia de habitat en Papa Uvas (Aljaraque, Huelva)». Homenaje a Luis Siret: 227-242. Sevilla.

Molina Lemos. L. (1980): «El poblado del Bronce I de El Lobo (Badajoz)». Noticiario Arqueológico Hispánico, 9: 93 127. Madrid.

MonTeIRo, R.; ZBYSzewSKI, G. y Veiga Ferreira, O. DA. (1971): "Nota preliminar sobre a Lapa prehistorica do Bugiow. Actas del I C.N.A., I: 107-120. Coimbra. 
Moure, J. A.; Fernández-Miranda, M. (1977): „El abrigo de Verdelpino (Cuenca). Noticia de los trabajos de 1976n. Trabajos de Prehistoria, 32: 31-83. Madrid.

Municio, L.; Ruiz.Gálvez, M. L. (1986): „Un nuevo yacimiento neolítico en la Meseta Norte: las cerámicas decoradas de la cueva de la Nogalera (Villaseca, Segovia)w. Numantia, II: 143-157. Soria.

OLIVEIRA, JoRge, V. (1983): «Em torno a alguns problemas do megalitismo europeun. Arqueologia, 8: 12-21. Porto.

Pinón VARela, F. (1987a): «Cuestiones sobre los constructores de sepulcros megaliticos en Huelva; problemas de una implantación». El megalitismo en la Peninsula Ibérica: 45-72. Madrid.

- (1987b): «La Edad del Cobre en el Sudoeste peninsular: claves de la periodización de un proceson. En M. Fernández-Miranda (Dir.): «El origen de la metalurgia en la Península Ibérica (Oviedo, agosto de 1987). Madrid, en prensa.

- (1988): „Los Vientos de La Zarcita (Santa Bárbara de Casa, Huelva). Resumen de la investigación sobre la Edad del Cobre en Huelva: 1981-1987w. Actas de las I Jornadas de Arqueologia Andaluza (Sevilla, enero de 1988). Folios mecanografiados.

Rivero de la Higuera, C. (1972-73): «Materiales inéditos de la Cueva de Boquique. Datos para una nueva sistematización de la Edad del Bronce en Extremadura. Zephyrus, XXIII-XXIV: 101-130. Salamanca.

Ruiz-Gálvez, M. L. (1984): «Reflexiones terminológicas en torno a la Edad del Bronce peninsular». Trabajos de Prehistoria, 41: 323-342. Madrid.

Ruiz Mata, D. (1983): «El yacimiento de la Edad del Bronce de Valencina de la Concepción (Sevilla) en el marco cultural del Bajo Guadalquivin. I Congreso de Historia en Andalucía: 183-208. Córdoba.

TAvares, C.; SoAres, J. (1977): «Contribuçao para o conhecimento dos povoados calcolíticos do Baixo Alentejo e Algarve». Setúbal Arqueológica, II-III: 179-272. Setúbal.

- (1981): „Prehistoria da area de Sines. Lisboa.

- (1985): «Monte da Tumba (Torrao). Eine befestige siedlung der Kupferzeit im Baixo Alentejo (Portugal)». Madrider Mitteilungen, 25: 1-21. Heidelberg.

VAL Recio, J. DEL (1983): "El Calcolitico precampaniforme en el Occidente de la Meseta. El yacimiento "Las Pozas" (Zamora). Memoria de Licenciatura inédita, leida en la Universidad de Valladolid.

VianA, A.; Dias de DeuS, A. (1955): «Notas para o estudo dos dolmens da regiao de Elvás». T.A.E., XV, 1-2: 1-55. Porto.

Whittle, E. H.; ARnaud, J. M. (1975): «Thermoluminiscent dating of Neolithic and Chalcolithic pottery from sites in Central Portugaln. Archaeometry, 17.1: 5-24. Cambridge.

Zamora, Canellada, A. (1976): «Excavaciones de la Cueva de la Vaquera, Torreiglesias-Segovia (Edad del Bronces. Excma. Diputación Provincial. Segovia. 